\title{
The Political Economy of Recasting the Constitutional Debate in Hong Kong
}

\section{Miron Mushkat and Roda Mushkat}

University of Hong Kong

\begin{abstract}
People obtain value, or gain utility, from procedures rather than merely from outcomes. Academic researchers are slowly and selectively coming to terms with this fact, but it is neither sufficiently nor widely appreciated by actors in Hong Kong's political arena, whether at the center or on the periphery. The territory is grappling with the issue of democratic reform - both its pace and scope- but the heated exchanges between the proponents and the opponents of representative government are confined to the outcome utility of the various constitutional proposals. It is essential to incorporate the procedural element into this incomplete picture.
\end{abstract}

\section{INTRODUCTION}

Economic change is normally accompanied by political change. Change in inEternational status also usually carries political implications. The Hong Kong experience thus qualifies as the exception to the rule. Rapid economic growth, featuring deep structural transformation, has not been matched by significant political adjustments. By the same token, the shedding of colonial identity, following the transfer of sovereignty from the United Kingdom to China, has not led to a meaningful enhancement of self-government and democratic representation. The political status quo remains largely intact - indeed, a retreat may have even taken place on a number of fronts.

The rigidity on the supply side, or unwillingness of those in Beijing and Hong Kong in a position to control the pace of institutional reform to contemplate a decisive shift toward universal franchise, has provoked a harsh response on the demand side. The clamor for genuinely representative government has grown progressively stronger, often manifesting itself in group-specific and nearly community-wide acts of defiance and protest. The desire to secure unfettered political participation has clearly solidified at the grass-roots level, particularly among middle class professionals. 
The imbalance between the supply side and the demand side has arguably resulted in strains within the overall system. As a result, Hong Kong may have consequently witnessed a "crisis of legitimacy," which, in turn, may have triggered a process of "political decay." The origins of the former may be traced to rising democratic aspirations in a complex urban environment, where the evolving social configuration is increasingly skewed toward the well-educated and cosmopolitan strata of society, against the backdrop of infringements of local autonomy by the post-1997 government of China. The lack of sensitivity displayed vis-à-vis these aspirations is viewed as a source of widespread criticism, in both direct and indirect form, regarding government institutions, and the policy establishment presiding over them. ${ }^{1}$

Political decay is another symptom of "reverse democratization." It apparently takes the shape of a material deterioration in government performance as evidenced, inter alia, by the adoption of a Third World-style personal rule at the apex of the executive branch, reliance on patron-client networks, politicization of the judiciary, cavalier attitude toward freedom in general and civil liberties in particular, indifference to public opinion, poor response to demands emanating from the grass-roots level, erratic policy formulation and implementation, symbolic manipulation and a propensity to play one segment of the community against another. ${ }^{2}$

Government effectiveness may also be adversely affected by stress within the policy machinery, largely attributable to the incoherence characterizing the political reform process. This stress reflects a growing degree of organizational "disarticulation." Specifically, given that the set-up amounts to "neither parliamentary fish nor presidential fowl, the executive, the bureaucracy and the legislature (which is divided within itself) each pursue their own agenda, punctuated by occasional skirmishes in the boundaries of their domains and by subterranean campaigns to extend their jurisdictions." ${ }^{3}$ The reasons "lie in the factors behind the formal power arrangements embedded in the Basic Law on the one hand, and the domestic politics of the transition on the other, both of which left an indelible and incompatible imprint on the way in which institutions actually work."4

A disarticulated policy network cannot, by definition, function smoothly. Strategies formulated are unlikely to be marked by great depth, congruity, and consistency. Strategy implementation may pose an even more serious challenge because stimuli from the sources of policy initiative are bound to dissipate in the face of centrifugal pressures impairing execution channels. This scarcely qualifies as a favorable backdrop insofar as maximizing societal performance is concerned, even in an environment where the private sector enjoys considerable autonomy and remains large relative to its public counterpart.

Un-accommodated demands for representative government are in themselves a sufficient cause for widespread disaffection at the grass-roots level. The deterioration in the quality of strategic management inevitably intensifies the sense of malaise and despondency. A vicious circle unfolds whereby this sentiment prompts pro-democracy activists, both individually and collectively, to pursue 
their goals in a form and on a scale that provokes a defensive and unproductive reaction on the part of the powers that be in Beijing and their "proxies" in Hong Kong. On the face of it, embracing universal franchise, sooner rather than later, and unambiguously rather than tentatively, appears to be the appropriate policy response to the imbalances that have emerged and the problems which they have spawned.

There is another side to this complicated picture, however. Representative government is undoubtedly conducive to accountability (including transparency), equity, and freedom. The verdict regarding efficiency, an equally important strategic goal, is less favorable. Public choice theorists, particularly those conducting research in the area of constitutional economics, have compellingly highlighted, albeit not necessarily in an uncontroversial fashion, institutional "failures" commonly encountered in democratic settings. These failures are not confined to the supply side of the political arena (i.e., bureaucrats and elected officials) but also manifest themselves on the demand side (i.e., among voters). ${ }^{5}$

Indeed, in economically mature yet otherwise, in certain crucial respects, shackled Hong Kong, the clamor for universal franchise, now rather than in the distant future, while strong, and increasingly so, has not extended across the entire societal spectrum. Some groups have not only refrained from providing active or tacit support but have voiced their objections to any hasty departures from the model of an "executive-led government." Subtle or not-so-subtle pressure from Beijing, as well as self-interest, may account for this stance, yet one has to acknowledge that it selectively reflects a genuine concern about the potentially adverse impact of far-reaching and not measured democratization on the performance of the proverbial "goose that lays the golden egg" (i.e., efficiency). ${ }^{6}$

The emotional intensity of the debate regarding the merits and demerits of dismantling the vestiges of authoritarian rule is surprisingly high given the historical backdrop and geo-political constraints. It is thus interesting to note that the debate evolves within an analytical framework. Both sides across the political divide employ, whether explicitly or implicitly, utilitarian arguments. The proponents of representative government emphasize the connection between this progressive institutional configuration and values such as accountability (including, again, transparency), equity, and freedom. Those who prefer to cling to the status quo lay stress on its efficiency-enhancing attributes. ${ }^{7}$

This dimension of the debate has been addressed in recent academic work, undertaken with a view to bringing the links between the competing systems of political management (democracy and consultative dictatorship; the instrumental variables) and the values which they supposedly reinforce into sharper focus. ${ }^{8}$ The studies completed do not remove all the conceptual ambiguities, but they arguably provide a clearer picture of the factors at play and the analytical structure binding them to each other. Nevertheless, the utilitarian logic used by the opposing ideological camps is incomplete, which detracts from the quality of the constitutional debate. The purpose of this paper is to identify a key missing element and suggest how it might be incorporated productively into the institutional reform agenda. 


\section{THE RELEVANCE OF PROCEDURE}

Social scientists, particularly those pursuing research in the field of microeconomics, have accorded considerable attention to the concept of "utility" since the advent of positivism in the 1930s. However, their application of the concept has largely been confined to outcomes. To state it more explicitly, they have chosen to view individual utility as the result of benefits and costs derived from instrumental outcomes. A powerful model of human behavior, albeit one resting on rather restrictive assumptions, has been constructed on this basis.

Outcome-induced utility, if stripped of its more esoteric connotations, is an everyday phenomenon of great theoretical and practical importance which merits the consideration given to it by social scientists, both those drawn toward model-building and those with an interest in policy analysis. The validity of this observation notwithstanding, it is legitimate to argue that outcomes are not the sole source of individual utility. Specifically, human well-being is also affected by the procedural aspects of social dynamics (e.g., individuals involved in lawsuits are generally less reluctant to accept a given judgment, even distinctly unfavorable, when they regard the court procedures as fair). ${ }^{9}$

The recognition that this is the case inevitably leads to the notion of "procedural utility," which implies that human well-being is a multi-dimensional construct not adequately represented through instrumental outputs in traditional-style economic utility functions. There is ample evidence to suggest that people care deeply about outcomes. At the same time, there is also evidence-not as quantitatively robust, because the work in this area is just beginning to gain momentum-supporting the idea that people also have preferences about how instrumental outcomes are generated. These preferences, in turn, give rise to procedural utility. ${ }^{10}$

It is a moot point whether the distinction between outcome utility and procedural utility is entirely valid from a pure academic perspective. Procedural configurations have an extrinsic value which is perhaps fundamentally no different from that associated with "other" outcomes. Nevertheless, the distinction is useful from a policy standpoint because of the tendency of applied social scientists to focus narrowly on the material dimension of outcomes (particularly monetary benefits) and because empirically-generated findings-selectively surveyed here-suggest that it may be justified on cognitive grounds (i.e., people perceive procedures as separate from outcomes and value them accordingly). There are thus compelling practical reasons for de-coupling the procedural side of utility from the outcome one and highlighting the policy relevance of the former.

The fine-tuning of the research agenda via a shift toward procedures is a healthy development for it allows us to equate utility broadly with well-being. It may thus be viewed as pleasure and pain, positive and negative sentiment, or life satisfaction. This should help to revive the original economic proposition that utility consists of everything that individuals value. Indeed, some of the research conducted recently in the field of behavioral economics directly addresses the reported subjective well-being, or happiness, experienced by actors operating in the economic arena. ${ }^{11}$ 
Procedural utility materializes because people have a sense of self. The concept incorporates a central tenet of social psychology into economics-namely, that people care about how they perceive themselves and how they are perceived by others. ${ }^{12}$ Procedural utility looms large in human functioning since procedures provide essential feedback information to the self by touching in various ways on the innate psychological needs of self-determination. Three such needs are deemed to be crucial by scholars working in this area: autonomy, relatedness, and competence. ${ }^{13}$

The need for autonomy is rooted in the desire to organize one's own actions, or to be causal. The need for relatedness stems from the inclination to feel connected to others through love and care, and being treated as an accepted and respected member within social groups. And the need for competence has its origins in the propensity to control the environment and perceive oneself as capable and effective. ${ }^{14}$ Different procedures may act as the source of different "procedural goods" fulfilling these innate needs and contributing in the process to human well-being, whether or not they impinge on instrumental outcomes as narrowly conceptualized by social scientists. ${ }^{15}$

An example might render this explanation more concrete. Thus, in a wellknown study, the researchers explored a situation where real-life litigants were involved in arbitration proceedings. At the end of the exercise, the court ordered an award, leaving the parties either to comply with the decision or reject it and opt for a trial. ${ }^{16}$ Social scientists, including those approaching the subject from a law-and-economics perspective, would traditionally examine such a situation by assessing the benefits and costs of accepting an award.

Indeed, litigant behavior validated to some extent the assumptions underlying this methodological position. Attitudes toward the court's decision were sensitive to instrumental outcomes such as the ratio between the actual award and the amount originally demanded, or the litigant's evaluation of whether the outcome was favorable or unfavorable (which could be viewed as a reasonable proxy for the expected net benefit of going to trial). Yet overall, the fairness of the arbitration procedure was found to be of greater importance for acceptance than instrumental outcomes. ${ }^{17}$

This result may be attributed to the fact that procedures apparently convey crucial feedback information to the self, thereby affecting individuals' well-being. Procedures that are regarded as fair are often those that give participants in social processes an effective "voice." Being provided with an opportunity to express views about issues concerning oneself generates procedural utility because it addresses innate needs for dimensions of self-determination such as autonomy and competence. And, since it is a vital signal about one's standing in a group, it impinges on innate needs of relatedness. ${ }^{18}$

Procedural utility is determined by many factors-economic, legal, organizational, political, and social-but it is convenient to group them into two broad categories. First, there is the procedural utility people gain from institutions as such. At the macro level, the principal institutional mechanisms for facilitating decision making are bargaining, democracy, hierarchy, and the price system/ market. ${ }^{19}$ People may derive procedural utility from these institutions because 
they affect their fundamental needs. For example, a constitution that safeguards civil liberties such as the freedom of speech may contribute tangibly to people's self-worth. On the other hand, a constitution that denies certain groups their legitimate political rights may undermine people's sense of self, its instrumental value notwithstanding. Institutions thus have a direct bearing on human well-being by addressing innate needs of autonomy, relatedness, and competence. ${ }^{20}$

Second, procedural utility is the inevitable product of the interaction between people. Participants in social processes assess actions directed toward them not just by the consequences, but also by their perceptions regarding the manner in which they are treated by others. This manner is shaped to a considerable extent by institutions which provide incentives, both directly and indirectly, for people in exchange relationships to treat each other in certain ways in most social situations. To illustrate, labor law and company statutes exert strong influence over the interaction between managers and employees. The corollary is that institutions also have a more complex link to human well-being due to the role they play in motivating and restricting people's actions vis-à-vis each other (hence qualifying as a key determinant of the sense of self from a micro perspective as well). ${ }^{21}$

At this stage of Hong Kong's constitutional evolution, close attention should be accorded to procedural utility obtained from democratic participation. There is a voluminous literature suggesting that this is an activity which provides people with a distinctly positive experience in a variety of cultural settings. ${ }^{22}$ The rights to participate in political decisions are a vital ingredient of any democratic constitutional configuration. They range from voting in elections, and launching and exercising voice through referenda, to running for a seat in the legislature. Citizens may gain procedural utility from such participation rights over and above the outcome generated in the political process because they enhance the sense of empowerment/autonomy, inclusion/relatedness, and effectiveness/competence. ${ }^{23}$

In a recent study, an attempt was made to ascertain in highly specific terms the procedural utility enjoyed by virtue of people being able to avail themselves of meaningful political participation rights. The researchers focused on the differences in status between nationals and foreigners. The former have the right to vote and access the political arena through other channels, while the latter cannot vote and have virtually no room for political maneuver. Nationals should thus derive more satisfaction from political participation rights than foreigners because of the procedural means at their disposal-a hypothesis that was tested in the Swiss context. ${ }^{24}$

Switzerland was chosen for this purpose for it is a country where one finds a remarkably high degree of variation in the political participation rights among citizens. In addition to elections, they can make use of direct democratic instruments (grass-root initiatives, referenda), which differ significantly from one canton to another. As a proxy measure for utility, an index of reported subjective well-being was employed to test the hypothesis. It is interesting to note that the overall utility effect from more comprehensive political participation rights, as reflected in reported satisfaction with life, was quite substantial. ${ }^{25}$ 
Citizens, as well as foreigners, living in jurisdictions with more developed political participation rights apparently fare considerably better in terms of their subjective well-being. However, the positive effect on reported satisfaction with life turned out to be much more modest for foreigners, a result attributable to their exclusion from the political process (the positive effect of participation rights was about three times larger for citizens than for foreigners, implying that procedural utility was a crucial factor in the psychological equation). The picture remained intact when several correlates of subjective well-being (particularly socio-demographic characteristics, employment status and household income) were controlled for. ${ }^{26}$

The issue of the procedural utility (or disutility!) obtained from a top-down policy management style (the term "executive-led government" perhaps does not fully capture the essence of this institutional pattern) should also be incorporated into Hong Kong's evolving constitutional agenda. The behavioral theories relied upon throughout this paper suggest that people prefer independence to being subject to hierarchical decision making. Specifically, hierarchy may be viewed as a source of procedural disutility because it undermines the innate needs of selfdetermination: autonomy and competence cannot be exercised effectively when authority flows from the top layers of the organizational structure to their bottom counterparts, and relatedness is also hindered in such circumstances. ${ }^{27}$

There is considerable empirical evidence to support this assertion. One study stands out in that respect for it addresses explicitly the relationship between hierarchy and procedural utility. The researchers involved sought to capitalize on the fact that earnings can basically be generated through two channels: a hierarchy (as an employee) and independently (as a self-employed person). Using individual panel data from Germany, Switzerland, and the United Kingdom, they established that self-employed people secure greater utility from their work (measured via job satisfaction) than employees, even if highly relevant instrumental outcomes such as the pay level and working hours are controlled for ${ }^{28}$

Another dimension of procedural utility which merits consideration in the current constitutional climate in Hong Kong is its link to due process. Pertinent insights are available across the social science spectrum, but those originating in the field of organizational studies are probably the most useful. Here, researchers consistently report that concerns for procedural faimess play a pivotal role in shaping the employment relationship. Procedural aspects identified as important include organizational policies and rules (e.g., providing advance notice for decisions and opportunities for voice), but they also extend to the interpersonal treatment of people. Again, the findings are consistent with the notion that participants in social processes value fair procedures over and above organizational outcomes. ${ }^{29}$

Due process needs to be examined in the broader context of the rule of law, in general and in the present Hong Kong constitutional context in particular. Indeed, this is an area where procedural fairness has been explored in a very thorough fashion. Many behaviorally-oriented legal scholars draw the conclusion that people react adversely to unfair procedures, regardless of the objective judgment made by a court of law. Perceived procedural unfairness consistently prompts individuals to rate the legitimacy of authorities and their satisfaction 
with a trial as fairly low and, rather interestingly, it also influences subsequent compliance behavior. ${ }^{30}$

One study has already been outlined because of its wider ramifications, but it may be desirable to highlight that work again because of its real-life focus. As noted, the researchers who undertook the investigation explored the acceptance of awards from court-ordered arbitration by actual litigants. Those involved included corporate entities and individuals engaged in litigation at federal-level American courts. The researchers observed that litigants who viewed the arbitration process as fair were much more likely to accept the court-ordered award (irrespective of the objective outcome). ${ }^{31}$

The decision whether to opt for a formal trial was driven most strongly by procedural fairness factors. This is remarkable, as the disputes considered had far-reaching financial implications (with the amount of money at stake as high as U.S. $\$ 800,000$ ). The objective size of the award and other instrumental variables also predicted acceptance, but to a much lesser extent. The findings thus demonstrate that utility from procedures plays a role in lawsuits over and above outcome utility. ${ }^{32}$

The issues of democratic participation (at least in the form associated with representative government), policy management style (top-down versus bottomup, or a mixture of the two), due process and the rule of law loom large on Hong Kong's constitutional agenda. Moreover, social science research has reached a critical mass and has solid empirical underpinnings. ${ }^{33}$ Nevertheless, the debate regarding constitutional progress, its complexity and intensity notwithstanding, is not properly grounded in the logic of procedural utility. By the same token, social science capabilities are not productively employed to enhance the understanding of public attitudes vis-à-vis strategic elements of the territory's procedural edifice. Given the prevailing conceptual ambiguities and ideological strains, it is essential to take steps toward reversing this trend.

\section{STRIKING A BALANCE}

The position adopted in this paper, while reflecting serious concerns and deep convictions, is not necessarily one that leads to the conclusion that procedural utility is the sole relevant factor in all circumstances or that it overshadows every other part of the picture. One should acknowledge that the distinction between procedure and outcome cannot always be readily drawn, both in theory and in practice. Economists thus normally express a preference for markets as allocation mechanisms, not just because markets seem to produce better outcomes than the alternatives (at least in terms of efficiency and freedom), but also because markets institutionalize a favored treatment of trading partners in interaction. ${ }^{34}$

Admittedly, some social philosophers evaluate procedures without any reference to the outcomes they produce. A libertarian such as Nozick is a prominent example. In his dissection of "right rules," personal liberties and rights of property are accorded such a high intrinsic value that any outcomes associated with them have no material bearing on the evaluation. ${ }^{35}$ However, even those who embrace this perspective cannot overlook the possibility that the consequences of such 
procedurally robust social order might prove to be extremely costly ("it can be shown that ... gigantic famines can actually take place in an economy that fulfills all the libertarian rights and entitlements specified in the Nozick system"). ${ }^{36}$

There are, hence, good reasons for taking procedural and outcome variables simultaneously into account when confronting constitutional choices. This may complicate matters because the two sets do not always reinforce each other. In the case of democratic participation rights, the procedure seems to produce positive procedural utility as well as better outcomes (subject to certain analytical qualifications and institutional adjustments) ${ }^{37}$ In other circumstances, procedure and outcome at times propel the decision-making system in different directions. Whenever this happens to be the prevailing pattern, there is inevitably a tradeoff between procedural and outcome concerns. The participants in Hong Kong's constitutional debate should be able to rise to the challenge, provided they recognize that procedural utility is a vital component of the modern policy maker's conceptual apparatus.

There are no tangible signs that a shift in this direction is about to materialize. As matters stand, a large and affluent metropolis, boasting a sophisticated physical and institutional infrastructure, and defining and promoting itself as "Asia's world city," is deeply divided over whether and when to embrace democracy. Cracks are also beginning to appear in the political façade regarding the commitment to due process and the rule of law. Those extolling the merits of the executive-led government model in its traditional form express misgivings about the risks to "prosperity" and "stability" (the local equivalent of efficiency) stemming from rapid political liberalization and overly constrained public authority. Those at the opposite end of the ideological spectrum counter by highlighting the adverse impact on the socio-economic system of practices that undermine accountability, equity, and freedom. The picture is drawn by actors employing mostly the vocabulary of outcome utility. To restore a modicum of balance, these vexed constitutional issues should also be approached from a procedural perspective.

\section{Endnotes}

1. S. H. Lo, Governing Hong Kong (New York: Nova Science, 2002).

2. Ibid.

3. I. Scott, "The Disarticulation of Hong Kong's Post-Handover Political System," China Journal 22 (January 2000): 29.

4. Ibid.

5. M. Mushkat and R. Mushkat, "The Political Economy of Constitutional Reform in an Externally-Constrained Environment," Journal of Malaysian and Comparative Law (forthcoming).

6. Ibid.

7. Ibid.

8. Ibid.; M. Mushkat and R. Mushkat, The Political Economy of Governance and Public Trust (Hong Kong: Faculty of Law, University of Hong Kong, 2004); M. Mushkat and R. Mushkat, Constitutional Economics and the Quest for Democratic Reform in Hong Kong (Hong Kong: Faculty of Law, University of Hong Kong, 2004); M. Mushkat and R. Mushkat, The 
Political Economy of Non-Majoritarian Institutions (Hong Kong: Faculty of Law, University of Hong Kong, 2004).

9. A. Sen, Collective Choice and Social Welfare (San Francisco: Holden-Day, 1970); B. S. Frey, M. Benz, and A. Stutzer, "Introducing Procedural Utility," Journal of Institutional and Theoretical Economics 160 (September 2004): 377-401.

10. A. Sen, Collective Choice; Frey, Benz and Stutzer, "Introducing Procedural Utility."

11. A. J. Oswald, "Happiness and Economic Performance," Economic Journal 107 (November 1997): 1815-31; B. S. Frey and A. Stutzer, Happiness and Economics (Princeton: Princeton University Press, 2002); B. S. Frey and A. Stutzer, "What Can Economists Learn from Happiness Research," Journal of Economic Literature 40 (June 2002): 402-35.

12. R. F. Baumeister, "The Self," in D. T. Gilbert, S. T. Fiske, and G. Lindzey, eds., The Handbook of Social Psychology (Oxford: Oxford University Press, 1998), 680-740.

13. E. L. Deci and R. M. Ryan, Intrinsic Motivation and Self-Determination in Human Behavior (New York: Plenum Press, 1985).

14. Ibid.

15. Frey, Benz, and Stutzer, "Introducing Procedural Utility."

16. E. A. Lind, et al., "Individual and Corporate Dispute Resolution," Administrative Science Quarterly 38 (June 1993): 224-51.

17. Ibid.

18. Frey, Benz, and Stutzer, "Introducing Procedural Utility."

19. Ibid.

20. Ibid.

21. Ibid.

22. R. E. Lane, The Loss of Happiness in Market Economies (New Haven: Yale University Press, 2000).

23. Ibid.

24. Frey, Benz, and Stutzer, "Introducing Procedural Utility."

25. Ibid.

26. Ibid.

27. Ibid.

28. B. A. Frey and M. Benz, Being Independent is a Great Thing (Zurich: Institute of Empirical Research in Economics, University of Zurich, 2002).

29. Y. Cohen-Charash and P. E. Spector, "The Role of Justice in Organizations," Organizational Behavior and Human Decision Processes 86 (November 2001): 278-321.

30. T. R. Tyler, Why People Obey the Law (New Haven: Yale University Press, 1990).

31. Lind et al., "Individual and Corporate Dispute Resolution."

32. Ibid.

33. Mushkat and Mushkat, The Political Economy of Governance and Public Trust.

34. J. M. Buchanan, Liberty, Market, and the State (Brighton: Wheatsheaf, 1986).

35. R. Nozick, Anarchy, State, and Utopia (New York: Basic Books, 1974). 12.

36. A. Sen, "Rationality and Social Choice," American Economic Review 85 (March 1995):

37. Mushkat and Mushkat, "The Political Economy of Constitutional Reform in an Externally-Constrained Environment"; Mushkat and Mushkat, Constitutional Economics and the Quest for Democratic Reform in Hong Kong; Mushkat and Mushkat, The Political Economy of Non-Majoritarian Institutions. 